\title{
Multiple Choice Testing Methods
}

\author{
Is it a Biased Method of Testing for Asian International Students? \\ Terry Gatfield, Griffith University, Australia \\ Stephen Anthony Larmar, Griffith University, Australia
}

\begin{abstract}
The use of objective multiple choice testing is now prevalent across most academic disciplines. This testing method has proved to be well suited to western approaches to teaching and learning, which tend to favour a more positivistic approach in education. However, with the growth in the Asian economies, especially China, the university sector has substantially increased enrolments of international students. Yet very little changes have been undertaken in our teaching approaches especially in the area of assessment. In addition very little research has been facilitated with respect to Chinese students and their learning styles within a western framework. This paper examines some of the characteristics of Chinese learning styles and specifically reviews multiple choice testing approaches with a view to establishing if Chinese international students are significantly disadvantaged by them. Specifically, it tests on a large sample of students if tests score results of Chinese students are significantly different to western students. The outcomes of the survey research indicated there are no substantial differences although Australian students spend less time on revision compared to Chinese students.
\end{abstract}

Keywords: Asian Students, Multiple Choice Testing, Asian Learning Styles

\section{Background - The Growth Context}

$\mathrm{A}$ USTRALIA IS A global player in the supply of international education in a sophisticated industry reported to be worth $\$ 4.2$ billion to the economy (Bohme, Daris,
Meares \& Pearce, 2002). Since the industry in Australia opened its doors to free market principles in 1987 the international higher education student body has increased from under 10,000 to currently over 210,000 (Selected Higher Education Statistics, 2004). The growth is illustrated in figure 1.

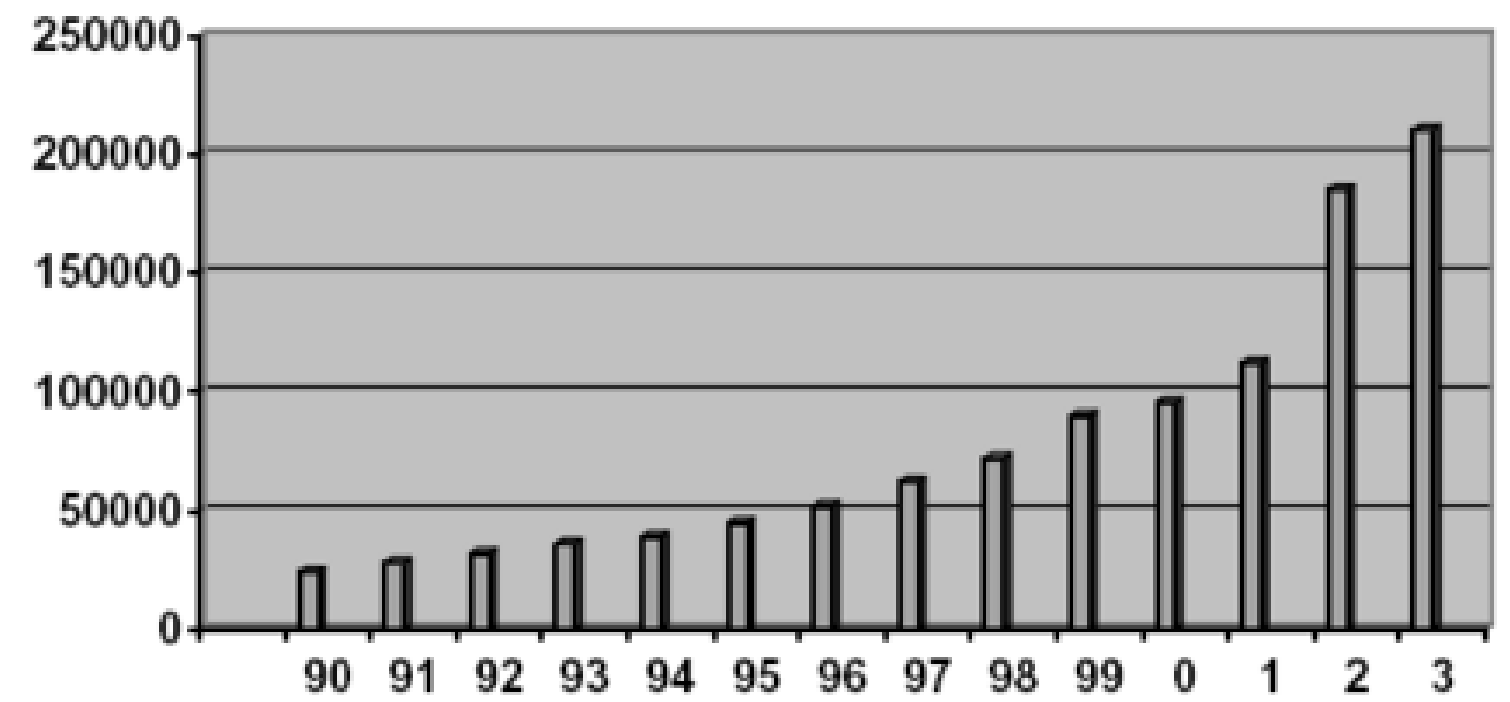

Figure 1: Growth in International Students Numbers, Source: Selected Higher Education Statistics - Various Years

Figure 1 is directed to higher education students. However, when the Vocational Education and Training, ELICOS colleges and schools are taken into consideration the number of international students in 2003 exceeded over 300,000 (IDP 2004).
The students are represented by at least 125 countries (Selected Higher Education Statistics, 2003).

International students now represent about $23 \%$ of the university student body (Selected Higher Educa- 
tion Statistics 2004) and the international student cohort have experienced a compound growth of over 10\% since 1987 (Selected Higher Education Statistics) and it is anticipated that it will expand to over $400 \%$ in the next two decades (2004, International Development Program). The ratio of international to domestic students varies from institution to institution. One commentator reports that in some universities nearly a third of all students are international with one institution earning $25 \%$ of its total revenue from this source (Marginson, 2002).

Table 1: Top Five Source Countries for Total Education Sectors, Source: IDP 2004

\begin{tabular}{|l|l|l|l|}
\hline Country & $\mathbf{2 0 0 2}$ & $\mathbf{2 0 0 4}$ & Growth \\
\hline China & 47931 & 57579 & $+20.1 \%$ \\
\hline Hong Kong & 22091 & 23083 & $+7.7 \%$ \\
\hline South Korea & 18658 & 22159 & $+18.8 \%$ \\
\hline Indonesia & 20985 & 20336 & $-3.1 \%$ \\
\hline Malaysia & 17530 & 19779 & $+12.8 \%$ \\
\hline Total all countries & 273,855 & 303,324 & $+10.8 \%$ \\
\hline
\end{tabular}

With respect to the disciplines selected for study, the business related area and information technologies are by far the largest international student areas with approximately two-thirds of students graduating from them (Marginson, 2002). The masters programs are the largest growing sub-sector of the international student cohorts (Selected Higher Education Statistics, 2004)

The data illustrated in table 1 includes both onshore and offshore student enrolments. The offshore component includes twinning arrangements and complete studies provided to the students in their own countries. The delivery methods are being served through a variety of sources including visiting lecturers, webbased flexible formats, video conferencing, online classrooms and traditional print-based formats. Distance education has now become the fastest-growing sector in Australian higher education. To indicate the significance that Australia places on distance education it is providing a $\$ 1.3$ billion joint program in conjunction with the World Bank for an online education for Africa and Asian countries (Marginson, 2002).

\section{Higher Education the Global Phenomenon}

The international movement in higher education is now substantial, however students have been travelling to other countries since 600BC (Altbach, Kelly \& Luyat, 1993). Yet, the growth in the past has been limited and by 1950 there were still only a mere 100,000 students studying in other countries other than their own (Gatfield \& McDonnell, 2004). It has been estimated that there are now in excess of 1.8 million international students hosted by more than 50 different countries (Bohme et.al, 2002). It is estimated that by 2025 the global international student population will increase to 7.2 million (Bohme, et al., 2002). The global distribution of international students is illustrated in figure 2 .

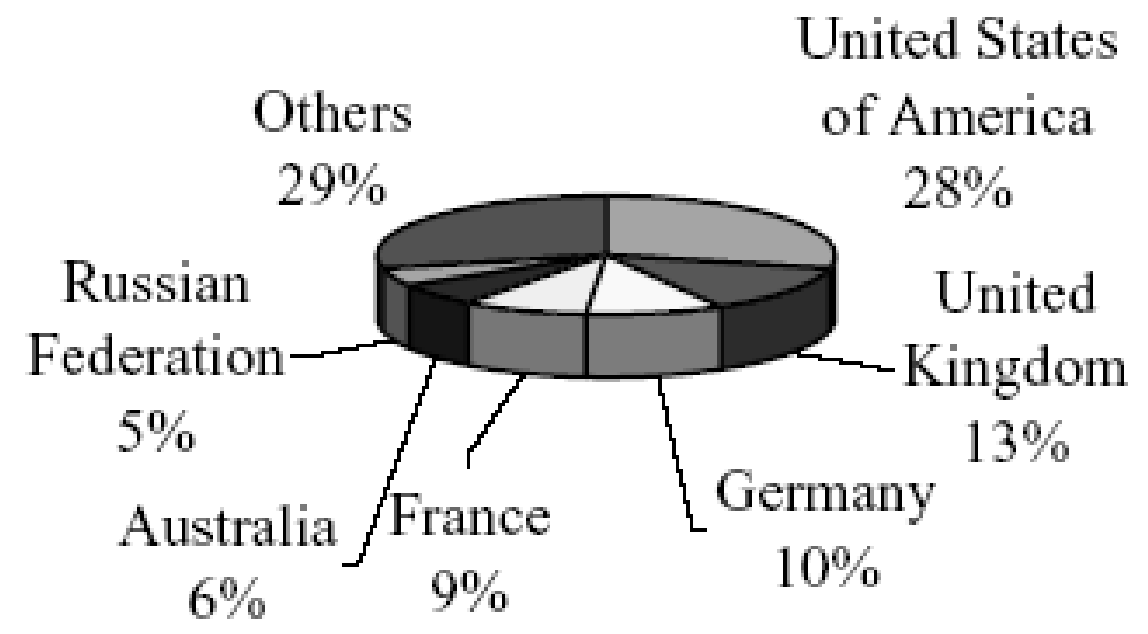

Figure 2: Major Host Countries of International Education, Source: UNESCO, 1999 
Each country has its own historical narrative, and whilst not ignoring them this paper is directed to the Australian situation, positioned at the higher education sector and focused on China. Although Australia has made only a fairly recent entry into the global educational arena and despite the population being only 20 million, and having only 37 public and 2 private higher education institutions, it now shares $6 \%$ of the world market (UNESCO 1999). This compares relatively favourable with USA who is the world's largest provider of education having over half a million international students (Bohm et al, 2002). However, the USA has a population of 17 times that of Australia but has less than four times the number of students (Marginson 2002).

\section{Future Trends and Australia}

Estimating future trends in international student numbers is no simple task. The first estimate with respect to student numbers and potential earnings was undertaken by the Department of Trade in conjunction with the Department of Education in 1985 in preparation of the move towards introducing fullfee paying international students (Gatfield \& McDonnell, 2004). It was believed that the potential market was going to be worth a total of $\$ 100$ million per year providing correct marketing strategies were introduced (Chua, 1988). A big gap from the current estimated value of the market value of over $\$ 4$ billion. This is $4000 \%$ higher then the original estimate.

Bohme et al. (2002), have undertaken a comprehensive analysis of future trends. The research interrogated data from 130 countries and projected forecasts based on income per capita, population, education participation rates and propensity to study abroad. The finding was that global demand for education would rise to over 7 million by 2025 . The projected trend can be seen in Figure 3.

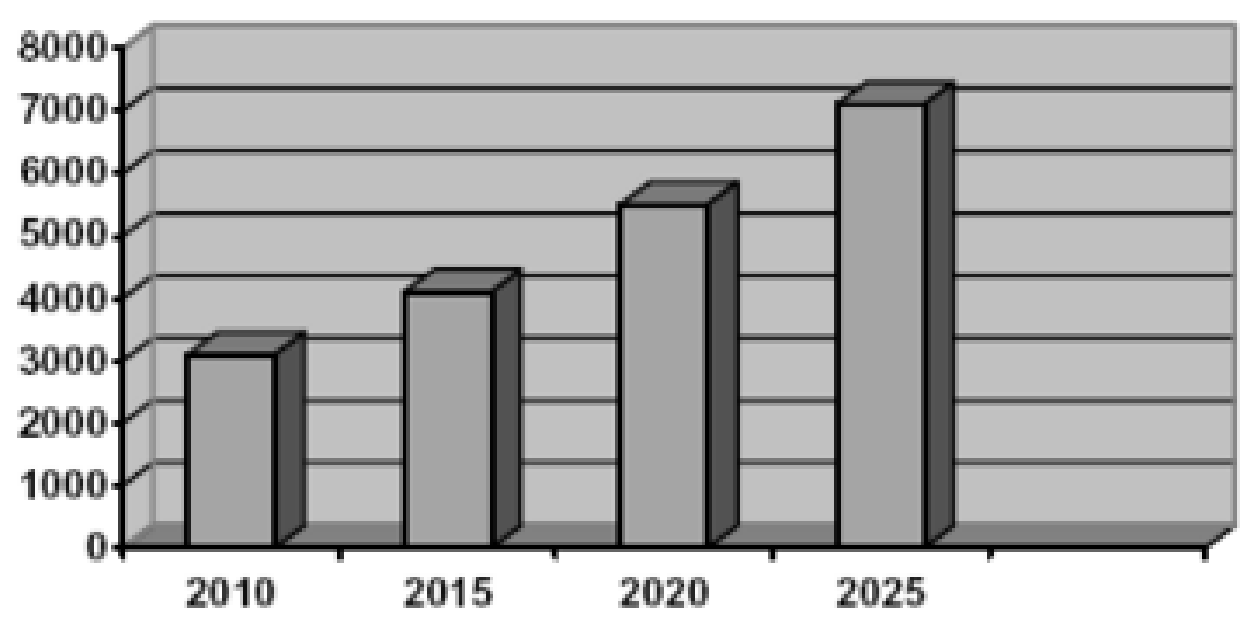

Figure 3: Projected Global Demand of International Education, Source: Adapted from Bohm et al., 2002

Regarding Australia's position it is estimated that by 2025 there will be 996,000 international students being served through higher education institutions.

A summary of the key aspects of the research as they relate to Australia and this paper are:

- The market demand for international students will grow substantially and by 2025 it will equate to having a $14 \%$ world market share

- The demand from is set to increase from $83 \%$ currently to about $92 \%$ by 2025

- Transnational, or offshore, demand will account for $44 \%$ of the total demand

- The value to the economy is expected to be in excess of $\$ 38$ billion in present day dollar terms.

- The most significant source country will be China

\section{China}

China is the new growth frontier for most western countries and especially Australia. The Chinese economy is currently the $6^{\text {th }}$ largest and it is on target to become the biggest by 2012. (Gatfield \& Wright 2006).

Since the 'open doors policy' of Deng Xiao Ping in December 1978 China's economy has changed markedly from a Soviet-style, centrally planned economy to that approaching a market orientation but remaining identified as 'a socialist market economy'. This represents a significant move forward from the 'open doors policy' when China was ranked as only the $32^{\text {nd }}$ largest economy (www.china.org.cn).

The results of the adoption of the new socialist market economy has led to a quadrupling of 
GDP to currently US\$1,439 billion (www.dfat.gov.au) where each of its 1.3 billion people now on average have a purchasing power parity of US $\$ 5,000$ per year ( www.china.org.cn ). From 1978 to 2004 China has received US\$500 billion in Foreign Direct Investment (DFAT 2005) and has been experiencing over
$9 \%$ compound GDP growth per year over the last decade (OECD 2004).

The trade dynamics of both China and Australia has changed significantly over time and the growth of exports and imports has accelerated significantly over the past 6 years as indicated in figure 4

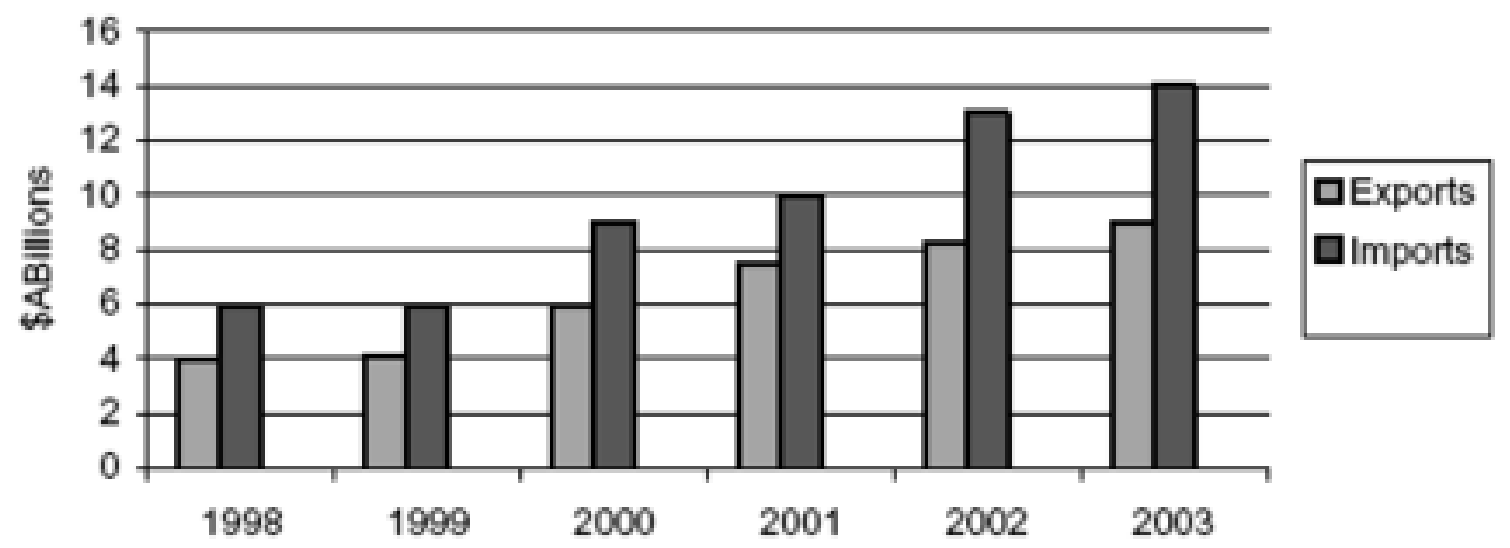

Figure 4: Australia and China Trade, Source dfat.gov.au

In 2004 Australia's merchandise exports to China were \$11 billion and now represent the country's second largest export market, following Japan. In addition, Chinese imports were A $\$ 17.9$ billion and represent the second largest import country (DFAT, 2005).

The second aspect is that there is an increasing deficit balance-of-trade with China. The higher education sector is one positive note that may assist in reducing the overall balance of trade. However, attention needs to be provided to increasing research into this culture especially as it reflects in teaching and learning practices.

\section{Teaching and Learning Approaches in Australia and the Chinese}

The literature suggests that student-learning styles are predetermined by their culture (Wong, 2004). The teaching and learning approaches adopted generally by Australian universities do not differentiate between nationalities of the students. In general, Australian universities adopt a constructivist mode of teaching and learning as opposed to an instructivist mode. In the constructivist mode meaning is understood not to be imposed or transmitted by direct action. Learning and knowledge is assumed to be created through the transformation of experience where emphasis is placed on the nature of the student as an individual learner. The student is understood to come to the learning situation with their own prior knowledge and personal cognitive and learning styles (http://www.lancs.ac.uk). This emphasis results in a shift in the definition of teaching from being exclusively about the structuring of the teaching activities to one where teaching is seen as a process of working co-operatively with learners to help them develop their own understanding (Ramsden, 1992).

By contrast it is generally considered that the Chinese approach is more directed towards constructivism. In this situation the student is largely viewed as a passive recipient in the education environment (Wong, 2004). According to Chan (1999), Chinese students are considered to be silent in class and taught not to question or challenge the teacher. This is reflective in their strong Confucian heritage culture where respect and authority to those in superior positions are seldom questioned. In addition, this is combined with what Hofstede identified as having the exceptional strong dominant strain of collectivism in thinking and decision making (Hofstede, 1980). It is often sighted that teaching and learning is seen largely as being didactic and generally text-bound (Kennedy, 2002).

As a consequence of Australian teaching and learning approaches there is a relative consistency in assessment principles with little or no adaptation to cross cultural needs. Assessment practices in Australia generally includes a mixture of multiple choice questions (MCQs), take home final exam, open book tests, short answer questions based on the text, short answer question from case studies, semester long projects and essay style questions. Whereas all the 
assessment methods have substantial merit in evaluating their effectiveness within the Chinese student context in Australia, this paper examines the issue of multiple choice questions. Specifically it addresses the research questions

RQ1 Is there a difference in results between Chinese students and Australian students with respect to MCQs?

RQ2Do Chinese students study for longer periods for MCQs tests than Australian students?

RQ3 Do Chinese students prefer to study in groups for MCQ tests more than Australian students?

\section{Literature Related to Multiple Choice Testing}

The quest of this age is echoed in the call for efficiency and effectiveness shaped by the influence and interests of key stakeholders. This is certainly true in the Australian higher education domain and reflects significantly in assessment practices. One assessment method that is now heavily relied upon and driven by the effectiveness and efficiency argument is the multiple choice approach.

The concept of MCQs is not new having been attributed to Kelly in 1914 (Bracey, 2000). Since that time it has been adopted in a variety of disciplines including physical education (Ayers, 2001), economics (Chan \& Kennedy, 2002), mathematics (Beller \& Gafni, 2000), psychology and fine arts ((Delgado $\&$ Prieto, 2003) and the physical sciences (www.ahe.cqu.edu.au).

In general the literature related to MCQ testing falls roughly into three main categories: firstly, constructing tests and applications in specific disciplines; secondly, the debate of higher order or deep learning and thirdly, evaluation, feedback and student perceptions. The literature in each of these areas is briefly highlighted. However, for those interested in a more detailed examination of the literature the reader is directed to the work of Roberts \& McInnerney (http://www.ahe.cqu.edu.au). These authors have compiled MCQ literature for the past ten years and associated influential articles from the past two decades in the teaching and learning discipline.

Constructing MCQ test has formed the largest part of the body of literature. Multiple choice tests by their nature have been seen to be controversial and the major problems stem from poorly or in appropriately constructed test items (Paxton, 2000). The literature on constructing tests falls into two areas: generic test design and test construction in specific disciplines. There are numerous texts on student assessment items and these usually include a chapter on objective tests but there are very few articles specifically devoted to constructing MCQ tests.
However in the generic area there are a number of writers including Isaacs (1994) who provided a multidisciplined guide and others such as Higgins and Tatham (2003) and Bracey (2000) who offer wider perspectives to assist educationalists. The second area related to specific disciplines and includes the works of: Ayers (2003) in the domain of physical education, recreation and dance; Chan and Kennedy (2002) with economics in general and O'Neill (2001) specifically in macro economics; Lowry (ww.ulh.ac.uk) in environmental science; Tretter and Jones (2003) in the physical sciences and Woodford and Bancroft (2004) in the discipline of information technology. However, very little research has been undertaken with respect to the Chinese student and MCQ testing.

\section{Research Methodology}

To examine the research questions a questionnaire was composed of questions addressing the three main research areas. The questionnaire is attached in the appendix.

The questionnaire was administered to two separate classes at a split campus University in Queensland Australia. The instrument was given to students just before the commencement of a compulsory midsemester test for a second year undergraduate business subject. The course was chosen because in the two campuses where it was taught the classes were very large and they contained a very high percentage of international students.

Students were requested to complete the questionnaire prior to commencing a mid-semester MCQ sixty-item test. Students had to complete all items and negative scoring was not undertaken. Each item had five possible responses. The test was constructed from a test bank supplied by the text book publishers. The same text and a similar test type had been used successfully through three successive years. However, previous years' tests were not made available for revision by students. All questions were selected carefully to ensure they were relevant to the student studying in an Australian context; that they were relatively short thus avoiding unnecessary complexities; that each question was based directly upon issues and statements found in the text and that the English grammar and structure was simple and clear. These issues were addressed to reduce, as far as possible, a bias between domestic and international students.

Students were informed before the commencement of the examination that the survey was being undertaken to understand and enhance teaching and learning classroom practices and that the results of the survey would not influence student grades in any way or form. Having the student responses so close to the examination and revision time ensured as high 
accuracy recall as possible. It was also asked if the students would provide a student number to enable their results at a later stage to be compared with the survey responses. However, students were not obliged to insert their student number if they felt uncomfortable about the situation - e.g., if they thought that the survey outcomes would affect their result. Of the total cohort of 593 students $12 \%$ did not record their student number. These students were eliminated from some of the statistical analyses. The directions concerning the test were given in written and oral forms. The surveys were completed and collected prior to the commencement of the examination to avoid contamination.

The data was entered into and analysed through SPSS v11.5.

\section{Sample Characteristics}

The age range was between 17-60 with a mean of 21.6 and a standard deviation of 3.5. The data, as expected, was skewed to the right with about $4.4 \%$ of the cohort over the age of 25. Males comprised $47 \%$ of the sample and females $53 \%$. An examination of the cross tabulations on the variables of interest showed that there were no unusual distribution differences between males and females. As the statist- ical tests undertaken in the analysis were robust there was not any need to transform the data.

\section{Results of the Research Questions}

RQ1 Is there a difference in results between Chinese students and Australian students with respect to MCQs?

With respect to the five nationality groups of Australian, Chinese, USA, European, Middle East and Other, the test scores revealed there were no significant differences. A one-way ANOVA was performed on nationality and test score. The results indicated there were no significant differences $\left(\mathrm{F}_{[5,241}=1.573, \mathrm{p}=.166\right)$. In examining the post hoc results the Australians $(n=249)$ and the Chinese group $(n=270)$ there was only a difference of 1.5 marks from a maximum score of 60 , i.e. $2.5 \%$.

RQ2Do Chinese students study for longer periods for a MCQ test than Australian students?

A simple comparisons of means was undertaken on length of time spent in revision for Australian and Asian students. For Australian students $(n=237)$ the mean was 8.24 hours. This compares with Asian students $(n=198)$ of 11.06 hours. Thus, the research questions indicate that Chinese students do spend more time studying for a MCQ test. Table 2 shows the distribution.

Table 2: Time Spent on Revision for MCQ Test

\begin{tabular}{|l|l|l|l|l|l|}
\hline Nationality & $1-5 \mathrm{hrs}$ & $6-10 \mathrm{hrs}$ & $11-15 \mathrm{hrs}$ & $16-20 \mathrm{hrs}$ & $>21$ hours \\
\hline Australian & $82(33 \%)$ & $77(31 \%)$ & $59(24 \%)$ & $19(8 \%)$ & $10(4 \%)$ \\
\hline Chinese & $33(13 \%)$ & $59(24 \%)$ & $62(25 \%)$ & $44(18 \%)$ & $49(20 \%)$ \\
\hline
\end{tabular}

In aggregating the two groups it was revealed that:

$24 \%$ of the sample spent $1-5$ hours in revision

$28 \%$ of the sample spent $6-10$ hours

$24 \%$ of the sample spent $11-15$ hours

$12 \%$ of the sample spent $16-20$ hours

$12 \%$ of the sample spent $>21$ hours

Note the calculation of the mean time spent in revision has been based on the central value of each of the first five categories. The final category has been ignored in the calculation as it does not have a central value. If the final category had been included the revision time gap would have increased substantially increasing support for the hypothesis.

RQ3 Do Chinese students prefer to study in groups for MCQ tests more than Australian students?

Australian students preferred to study with a partner or in a group on only $10 \%$ of occasions. By contrast Chinese international students pre- ferred to study on $17 \%$ of occasions with a partner or in a group.

\section{Additional Research on Qualitative Data}

No research questions were generated for this part of the analysis. For the reasons why students liked MCQs the written open ended responses were examined and coded into six categories:

1. Easy to answer and guess

2. Answers provided - not difficult on the memory

3. No difficulties with language and spelling -easy for non English speakers

4. No stress on the student

5. Limited possibilities

6. Other

Only the first three categories were examined as only these had a weight of over $5 \%$ responses. In the first category there were a similar number of responsea by Australian and Chinese students with about 
$63 \%$ who considered that 'the answers were easy to guess'. This was followed by $18 \%$ of the respondents saying 'having the answers provided' was important to them. Third, with $8 \%$ responses was the category of 'no difficulties with language and spelling' with the majority of the instances being attributed to the Chinese students.

With respect to the reasons why students did not like MCQs the responses were coded into five categories

\section{Confusing}

2. Does not test ability

3. Tough because of too many questions

4. Needs considerable concentration and reading

5. Other

The analysis 'dislike' categories were restricted to the first three as only these recorded greater than $5 \%$ responses. Seventy-three percent stated that MCQs were confusing. Secondly, 14\% considered that they did not test their ability and thirdly, $7 \%$ recorded that there were too many questions and the questions were tough.

It should be noted that the response rate for the 'like' category was $32 \%$ and for the 'dislike' category $53 \%$. The position of 'neutrality' was not measured but can be taken by inference.

\section{Discussion and Implications}

The first research question related to the possible discrimination issue of MCQ tests is important. The results indicated that in the area of nationality there was no difference in marks between the groups under investigation. This should assist in arresting some of the contentious issue in the literature (see for example the discussion of Beller and Gafni, 2000). To have found that there was a bias one way or the other would have indicated that MCQ tests were discriminatory and could be considered a questionably invalid instrument for use in higher education. There should be confidence by academics in administering MCQ tests based on the non-discriminatory line of nationality.

The second research question, directed to the issue of revision time it was found that the Australian student, on average, spends at least 8 hours and the Chinese student spends at least 11 hours in the same activity for a MCQ test. For the Chinese student there is usually a handicap in overcoming English language difficulties and especially in the use of unusual disciplinary jargon and that is sometimes coupled with complex western constructs. Further, the Chinese student has to become familiar with western concepts and educational practices. This may be compounded by the Chinese cultural background where students usually live in university dormitories, often start classes at 8:00 in the morning and may stay studying in classrooms till very late at night - perhaps much to their credit.

The third research question, directed to group study, demonstrates that MCQ test revision time is extended substantially by the Chinese student. It may still be considered that group learning is advantageous and this contexture is upheld substantially through organisational behavioural research. It is suggested that group revision should be encouraged as it may allow a structured and organised environment which facilitates a creative deep learning process to emerge combined with time efficiency and focus.

\section{Areas of Future Research}

With the increase in MCQ testing it is suggested there should be a call to examine the testing approach to establish the links with student preferred learning styles. Further, there is a need to undertake research through a controlled study to establish if deep learning does take place with MCQ testing. This last factor remains a highly contentious issue. Further, additional qualitative research needs to be undertaken in the area of why students strongly support MCQ testing. If it is mainly focused on the 'easiest option' without substantial learning objectives being satisfied then the concept must be re-evaluated. Unfortunately, as highlighted earlier, the caveat remains 'the call is for sound research question design to meaningfully evaluate what needs to be learnt'. There is much anecdotal information to indicate this is not always undertaken. This paper's research has been undertaken from the perspective of one discipline and replication is called for.

\section{Conclusions}

This research demonstrates that it does not favour any nationality group in particular the Chinese students. On that factor MCQ tests should be considered to be a non-biased method of evaluating student understanding. As was anticipated Chinese students revise for longer periods than Australian students and they engaged in more group study practices. However, neither of those factors were instrumental in influencing test scores. This research confirms student's affirmation of the MCQ test instrument but it does not address the vexed question of quality learning outcomes. That remains to be addressed by further research. 


\section{References}

Altbach, P.G., Kelly, D.H. \& Luyat, Y.G-M., 1993, Research on Foreign Students and International Study, Prager, New York.

Ayers, S.F., 2001, 'Developing quality multiple choice tests for physical education, Journal of Physical Education, Recreation and Dance, vol, 72, issue, 6., pps 23-30.

Beller, M. \& Gafni, N., 2000, Sex Roles, vol, 42, issue, 1/2, pps 1-21.

Bohme, C., Daris, F., Meares, H., \& Pearce, T. (2002). Global student mobility 2025: Forecasts of the global demand for international higher education. Canberra.

Bracey, G.W., 2001, Thinking about tests: A short primer in assessment literacy, The American Youth Forum, Washington D.C.

Chan, S, 1999, The Chinese learner - a question of style, Education and Training, vol, 41, no. 6/7.

Chan N. and Kennedy, P.E., 2002, 'Are multiple-choice exams easier for economics students?, Southern Economic Journal, vol 68 , issue, 4.

Delgado, A.R \& Prieto, G., 2003, The effect of item feedback on multiple-choice test responses, British Journal of Psychology, vol., 94, part 1 pps 73- 92

DFAT, 2005, Australia-China Free Trade Agreement Joint Feasibility Brochure.

Gatfield, T.J., McDonnell, J, 2004, Marketing Higher Education, Australia and New Zealand International Business Association, Canberra.

Gatfield, T.J, \& Wright, O, 2006 China Market Entry Strategies: A Case Study on Sister State and Sister City Relationships in Queensland, Proceedings Academy of World Business Conference Proceedings,(in press).

Higgins, E \& Tatham, L., 2003, Assessing by multiple choice questions tests, UKCLE Resource Bank, Manchester Metropolitan University, Manchester.

Hofstede, G. 1980, Culture's Consequences: international differences in work-related values, Sage, California.

Kennedy, P., 2002, Learning cultures and learning styles: Myth-understandings about adult (Hong-Kong) Chinese learners, International Journal of Life-Long Education, vol., 21, no., 5

International Development Program, (2004), Australia's Exports of Education Services, AGPS, Canberra.

Isaacs, G., 1994, Multiple Choice Testing, HERDSA Green Guide, NSW.

Marginson, S. (2002), Education in a global market, http://aaup.org/publications/Academe/2002/02/mjmar.htm

O'Neill, P.B., 2001, Essay verses multiple choice exams; an experiment in the principles of macro economics, American Economist, vol, 45, issue 1; pps 62-69.

Paxton, M., 2000, A linguistic perspective on multiple choice questioning, Assessment and Evaluation in Higher Education, vol, 25, issue 2, pps 109-130.

Ramsden, P. 1992, Learning to teach in Higher Education, Routledge, London.

Selected Higher Education Statistics, Department of Education, Science and Training, AGPS, Canberra.

Tretter, T.R, \& Jones, M.G, 2003, Relationship Between Inquiry-Base Teaching and Physical Science Stardardised Test Scores, School of Science and Mathematics, vol.1, issue 7., pps 345-355.

United Nations Educational, Scientific and Cultural Organisation (UNESCO), (1999). Statistical y earbook. Paris: UNESCO.

Woodford, K., \& Bancroft, P., 2004, Using multiple choice questions effectively in Information Technology education. Beyond the Comfort Zone: Proceedings of the 21 st ASCILITE Conference, Perth. Pps 948-955.

Yunker, B.D, 1999, Adding authenticity to traditional multiple choice test formats, Education, vol., 120, issue 1, pp82-88.

Wong, J.K.K., 2004, Are styles of Asian International students culturally or contextually bound?, International Education Journal, vol., 4, no., 4.

Zeidner, M., 1987, Essay versus multiple-choice type classroom exams: the student's perspective. Journal of Educational Research, vol, 80, no., 6, pps. 352-358.

Web References

http://www.ahe.cqu.edu.au/MCQ.htm.

http://www.answers.com/main/ntquery;jsessionid=2fbleg379oi?method=4\&dsid=22

http://www.china.org.cn/e-china/openings/sez.htm

http://www.dfat.gov.au

http://www.lancs.ac.uk/palatine/s-v-presentations/websterpaper.htm

http://www.ulh.ac.uk/elen/

\section{Appendix - Multiple Choice Questionnaire}

To assist lecturers gain an more informed perspective on developing student friendly assessment methods it would be appreciated if you complete this questionnaire. You are under no obligation to do this. It will only take about 5 minutes. Only aggregate results will be used and your name and student number will not appear in any of the results. The outcomes of this survey will have no impact on the results of the test. 
Student number (optional)

Age $\square \quad$ Part time $\square$ Full time $\square \quad$ Male $\square \quad$ Female $\square$

Nationality

$\begin{array}{cccc}\text { Australian } \square & \text { Asian } \square & \text { USA } \square & \text { European }\end{array}$

For multiple choice question exams I normally study?

on my own $\square \quad$ with a partner $\square \quad$ in a group

How many hours did you study for this exam?

1-5hours $\square$ 6-10hours $\square$ 11-15hours $\square$ 16-20hours $\square>21$ hours

When did you start studying for this exam?

A day ago $\square$ 2-5 days ago $\square$ 6-10 days ago $\square$ 11-15 days ago $\square>16$ days ago $\square$

Please provide comments on -

The reasons why I like multiple-choice questions are:

The reasons why I dislike multiple-choice questions are:

\section{About the Authors}

Dr Terry Gatfield

Dr Terry Gatfield is a senior lecturer in the Department of Marketing at Griffith University Queensland Australia. He has published over 80 articals with a primary focus on consumer behaviour in an international marketing context. As a function of improving teaching and learning practices he frequently engages in class-room research practices especially as they relate to international students. However, his primary research focus is on China where he makes frequent visits with his teaching and research interests.

Dr Stephen Anthony Larmar

Stephen has worked for the past twelve years in education and psychology. He has a particular interest in counselling psychology and early intervention and prevention strategies for children and families at-risk of conduct problems. He has recently submitted his doctoral thesis in psychology where his research focussed on the evaluation of an early intervention and prevention program for children with conduct problems. He is currently working as a full-time lecturer in the School of Human Services at Griffith University, Queensland, Australia, where he teaches counselling and psychology to both undergraduate and post graduate students. 